\title{
Visual information processing after severe closed head injury: effects of forward and backward masking
}

\author{
Audrey J Mattson, Harvey S Levin, Bruno G Breitmeyer
}

\begin{abstract}
Three tachistoscopic tasks were employed to assess whether survivors of severe closed head injury (CHI) exhibit a disturbance of information processing within peripheral and/or central visual pathways. Twelve survivors of severe CHI and 12 individually matched control subjects completed a recognition threshold (no mask) task, a monoptic, forward masking by visual noise task (to assess processing within relatively peripheral pathways), and a dichoptic, backward masking by pattern task (to assess processing within central pathways). For each experimental procedure, the minimum exposure durations required by subjects to identify correctly single consonants and triple consonants were determined. Survivors of severe CHI showed deficits on all three visual tasks. Both groups also had higher threshold durations for the more complex stimuli (triple $v$ single consonants), but differences in threshold were greater in the patients with CHI. The degree of perceptual impairment exhibited by patients with CHI was highly variable and not consistently related to injury characteristics or residual motor or speech and language impariment.
\end{abstract}

$(尹$ Neurol Neurosurg Psychiatry 1994;57:818-824)

Survivors of severe closed head injury (CHI) exhibit information processing deficits on complex cognitive tasks such as serial calculation and choice reaction time. ${ }^{1-3}$ Few studies, however, have investigated the effects of $\mathrm{CHI}$ on the processing of early, perceptual processing. ${ }^{4}$ Ruesch ${ }^{5}$ examined the apperception of tachistoscopically presented three digit numbers in patients with acute and chronic CHI. $\mathrm{He}$ found that, compared with controls, the minimum exposure duration required for identification of the numbers was increased by a third in previously injured patients, and by nearly $150 \%$ in acute cases. Hannay and coworkers $^{6}$ subsequently studied tachistoscopic perception of patterns of consonants presented vertically in central vision in groups of patients after mild, moderate, or severe $\mathrm{CHI}$ and in 10 controls. The median time since injury was five months, and patients with visual field defects were excluded from the study. Hannay et $a l^{6}$ found that the recognition thresholds (exposure duration) of the patients with $\mathrm{CHI}$ were significantly longer than those of controls, but they did not vary with severity of injury. These studies indicate that perceptual processing within the visual modality is disrupted after head trauma.

Visual masking has been used extensively to study visual perception within an information processing framework, ${ }^{78}$ to assess developmental changes in the rate of visual information processing, ${ }^{9-11}$ and to document reductions in visual processing speed in patients with various neurological disorders, including dyslexia ${ }^{12}$ and dementia. ${ }^{13}$ Also, through the use of both forward and backward visual masking, researchers have been able to investigate processing within peripheral visual pathways (for example, retina to striate cortex) and central (cortical) visual pathways ${ }^{14}$ relatively independently.

Forward masking effects are strong under monoptic presentation but consistently weak under dichoptic presentation. ${ }^{14}$ This finding indicates that the perceptual interference caused by forward masking occurs primarily within more peripheral visual pathways. Forward masking effects presumably reflect the integration of neural impulses generated by the two stimuli as they travel from the retina to the cortex, much like a photographic double exposure. The interference, therefore, occurs at a preiconic level of visual processing.

Backward masking effects, by contrast, can originate in relatively peripheral or central visual pathways. Turvey ${ }^{14}$ inferred that backward masking by noise or light occurs peripherally, because masking occurs with monoptic or binocular presentation of the stimuli, but not under dichoptic viewing. Turvey found, however, that backward masking effects can be obtained dichoptically when a pattern mask is used (the mask shares figural characteristics with the target stimulus). This indicates that backward masking by pattern can occur at a relatively late stage in the cortical processing of visual information. ${ }^{14}$ Central masking effects presumably reflect the interruption, or termination, of the cortical processing of a target stimulus by the subsequent presentation of the mask, ${ }^{14}$ and can occur at preiconic or posticonic information processing stages. ${ }^{15}$

The present study employed a monoptic, forward masking by visual noise and a dichoptic, backward masking by pattern to determine whether $\mathrm{CHI}$ results in a disruption of visual information processing within peripheral or 
central visual pathways, or both. The study also investigated whether $\mathrm{CHI}$ differentially disrupts the processing of complex, as opposed to simple, visual information by varying the number of elements (single consonants, consonant trigrams) contained in the target stimuli.

\begin{abstract}
Methods
SUBJECTS

Twelve young adults who had sustained severe $\mathrm{CHI}$ and 12 controls individually matched for age, sex, race, and education level were included in the study (table 1). Subjects in both groups had corrected visual acuity of $20 / 40$ or greater and no history of previous head trauma, substance abuse, or other neuropsychiatric disorder. Informed consent, and parental consent when necessary, was obtained, and subjects in both groups were compensated for their participation.

The patients with $\mathrm{CHI}$ had been injured for at least one year before testing (table 2), and were recruited through either the University of Texas Medical Branch or the Transitional Learning Community in Galveston, Texas. Severe CHI was defined as non-missile trauma resulting in a Glasgow coma scale (GCS) score of 8 or less. ${ }^{16}$ In addition, all patients with $\mathrm{CHI}$ had a duration of coma (inability to obey commands) exceeding 24 hours, which ranged from six days to about five months. Accurate estimates of coma duration, however, were not available for all CHI patients. Table 1 summarises other clinical features of the $\mathrm{CHI}$ group.
\end{abstract}

Table 1 Demographic features of closed head injury (CHI) and control groups

\begin{tabular}{|c|c|c|c|c|}
\hline & $\mathrm{CHI}$ & Control & $t$ & p Value \\
\hline No & 12 & 12 & & \\
\hline Age (mean (SD)) & $25 \cdot 1(3.9)$ & $25 \cdot 2(4 \cdot 6)$ & -0.096 & $0.924 \mathrm{NS}$ \\
\hline Education (mean (SD)) & $11.7(1 \cdot 3)$ & $12 \cdot 0(0 \cdot 9)$ & -0.642 & $0.528 \mathrm{NS}$ \\
\hline $\operatorname{Sex}(M / F)^{\star}$ & $9 / 3$ & $9 / 3$ & & \\
\hline \multicolumn{5}{|l|}{ Race ${ }^{\star}:$} \\
\hline White & 9 & 8 & & \\
\hline Hispanic & 2 & 3 & & \\
\hline Black & 1 & 1 & & \\
\hline
\end{tabular}

${ }^{\star}$ NS ( $p>0.05$, Fisher's exact method analyses).

\section{Screening procedures}

Eye dominance was determined and subjects' visual fields were mapped using a tangent screen. ${ }^{17}$ The maps were then evaluated by an optometrist. One CHI patient had a left homonymous hemianopia (with macular sparing) and a constricted right visual field, four patients had bilateral constricted visual fields, and one head injured patient had a unilateral constricted visual field. Two control subjects evidenced a unilateral constricted visual field, and one had bilateral constricted visual fields.

A short set of neuropsychological measures was also administered. General intellectual ability was estimated by using the block design and vocabulary subtests of the Wechsler adult intelligence scale-revised (WAIS-R ${ }^{18}$ ). These tests were not readministered when WAIS-R scores obtained within the preceding 12 months were available, provided that the patient had been evaluated at least one year after injury. Selective attention was assessed using a letter cancellation task constructed by the investigators. Six rows of 15 letters were included. The number of target letters to be detected varied from one to three. The two variables calculated for the purpose of this study were the total time to complete the six conditions and the percentage of target letters detected. Fine motor speed was assessed on the preferred and non-preferred hands with the finger tapping subtest of the Halstead-Reitan battery. ${ }^{19}$ As seen in table 3, the CHI group was impaired relative to the controls on all measures except WAIS-R vocabulary.

\section{EXPERIMENTAL PROCEDURES} Apparatus

A Gerbrands three channel tachistoscope (Model T-3A) with three semiautomatic card backs was employed. Luminance was equalised across the fields by a minimal flicker technique. Polarising filters were used to present stimuli dichoptically (backward masking task) and monoptically (recognition threshold and forward masking tasks).

Stimuli

Target and masking stimuli appeared in

Table 2 Clinical features of closed head injury (CHI) group

\begin{tabular}{|c|c|c|c|c|c|c|c|}
\hline $\begin{array}{l}\text { Patient } \\
\text { No }\end{array}$ & $\begin{array}{l}\text { Injury } \\
\text { to test } \\
\text { interval }\end{array}$ & $\begin{array}{l}\text { Glasgow } \\
\text { coma } \\
\text { scale }\end{array}$ & $\begin{array}{l}\text { External } \\
\text { cause of } \\
\text { CHI }\end{array}$ & Complications & $C T$ findings & Motor deficits & $\begin{array}{l}\text { Speech/language } \\
\text { impairments }\end{array}$ \\
\hline $\begin{array}{l}01 \\
02 \\
03 \\
04 \\
05\end{array}$ & $\begin{array}{l}2 \cdot 7 \\
7 \cdot 0 \\
3 \cdot 5 \\
1 \cdot 1 \\
1 \cdot 7\end{array}$ & $\begin{array}{l}4 \\
3 \\
3 \\
5 \\
4\end{array}$ & $\begin{array}{l}\text { MVA } \\
\text { MVA } \\
\text { Hit and run } \\
\text { Assault } \\
\text { MVA }\end{array}$ & $\begin{array}{l}\text { Pulmonary } \\
\text { Anoxia } \\
\text { Multiple trauma } \\
\overline{\text { Multiple trauma }}\end{array}$ & $\begin{array}{l}\text { L-F/P SDH, midline shift to } \mathrm{R} \\
\mathrm{R}-\mathrm{T} \text { contusion brain stem lesion } \\
\text { L-F/T SDH } \\
\text { R-F haematoma, oedema } \\
\text { L-BS contusion, R-F/P and L-F } \\
\text { subdural hyoromas }\end{array}$ & 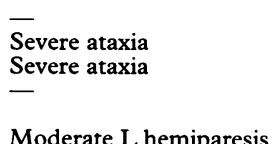 & 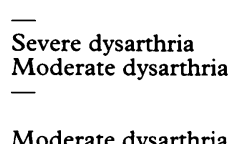 \\
\hline $\begin{array}{l}06 \\
07 \\
08 \\
09 \\
10 \\
11\end{array}$ & $\begin{array}{l}2 \cdot 0 \\
4 \cdot 1 \\
3 \cdot 7 \\
2 \cdot 5 \\
1 \cdot 9 \\
2 \cdot 0\end{array}$ & $\begin{array}{l}7 \\
6 \\
4 \\
4 \\
4 \\
8\end{array}$ & $\begin{array}{l}\text { MVA } \\
\text { MVA } \\
\text { MVA } \\
\text { MVA } \\
\text { MVA } \\
\text { MVA }\end{array}$ & $\begin{array}{l}\text { CSF otorrhoea } \\
\text { Increased ICP } \\
\overline{\text { Anoxia, increased ICP }} \\
\overline{\text { Pulmonary }}\end{array}$ & $\begin{array}{l}\text { subdural hygromas } \\
\text { R-T tip contusion } \\
\text { Oedema } \\
\text { L-F SDH, L-T contusion } \\
\text { B-F hygromas } \\
\text { R-F/P SDH } \\
\text { R-F contusion; L-P contusion; }\end{array}$ & $\begin{array}{l}\text { Moderate L hemiparesis } \\
\text { Mild L hemiparesis } \\
\text { Mild ataxia } \\
\text { Mild R hemiparesis } \\
\text { Moderate bradykinesia } \\
\text { - }\end{array}$ & $\begin{array}{l}\text { Moderate dysarthria } \\
= \\
\overline{-} \\
\text { Mild dysarthria } \\
\text { Mild dysarthria }\end{array}$ \\
\hline 12 & $2 \cdot 6$ & 5 & MVA & Pulmonary & $\begin{array}{l}\text { B-punctate haemorrhages, cavity } \\
\text { in R-basal ganglia }\end{array}$ & L hemiplegia & $\begin{array}{l}\text { Mild recept aphasia } \\
\text { _ }\end{array}$ \\
\hline
\end{tabular}

Ratings of language and motor function based on observation during testing, reports by staff at residential rehabilitation facility, and family members' report; MVA = motor vehicle accident; ICP = intracranial pressure; CSF = cerebrospinal fluid; $R=$ right; $L=$ left; $B=$ bilateral; SDH = subdural haematoma;

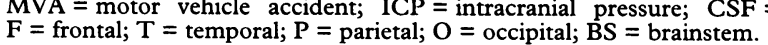


Table 3 Group comparisons on neuropsychological measures

\begin{tabular}{|c|c|c|c|c|}
\hline & $\begin{array}{l}C H I \\
(n=12)\end{array}$ & $\begin{array}{l}\text { Controls } \\
(n=12)\end{array}$ & $t$ & $p$ Value \\
\hline $\begin{array}{l}\text { WAIS-R subtests (age scaled scores): } \\
\text { Block design (mean (SD)) } \\
\text { Vocabulary (mean (SD)) }\end{array}$ & $\begin{array}{l}7 \cdot 1(2 \cdot 4) \\
7 \cdot 2(1 \cdot 9)\end{array}$ & $\begin{array}{l}9 \cdot 8(2 \cdot 1) \\
8 \cdot 1(1 \cdot 9)\end{array}$ & $\begin{array}{l}-2.91 \\
-1.17\end{array}$ & $\begin{array}{l}<0.01 \\
\text { NS }\end{array}$ \\
\hline $\begin{array}{l}\text { Finger tapping: } \\
\text { Dominant hand (mean (SD)) } \\
\text { Nondominant hand (mean (SD)) }\end{array}$ & $\begin{array}{l}34 \cdot 5(8 \cdot 3) \\
27 \cdot 7(9 \cdot 6)\end{array}$ & $\begin{array}{l}49 \cdot 2(5 \cdot 4) \\
44 \cdot 4(5 \cdot 8)\end{array}$ & $\begin{array}{l}5 \cdot 14 \\
5 \cdot 14\end{array}$ & $\begin{array}{l}<0.0001 \\
<0.0001\end{array}$ \\
\hline $\begin{array}{l}\text { Selective attention task: } \\
\text { Total time (s; mean (SD)) } \\
\text { Total \% correct (mean (SD)) }\end{array}$ & $\begin{array}{c}519(209) \\
91.9(4 \cdot 7)\end{array}$ & $\begin{array}{c}205(53) \\
95 \cdot 3(2 \cdot 8)\end{array}$ & $\begin{array}{r}5 \cdot 04 \\
-2 \cdot 15\end{array}$ & $\begin{array}{l}<0.001 \\
<0.05\end{array}$ \\
\hline
\end{tabular}

the centre of white stimulus cards. Target stimuli and the pattern mask were constructed from dry transfer letters (Chartpak-helvica medium, 24 point). The pattern mask was constructed by compiling fragments of angled and curved letters in a random overlapping pattern. The visual noise mask consisted of a chequerboard pattern with $50 \%$ of the squares darkened in a random pattern.

Target stimuli consisted of a single consonant or three consonants. Three unique sets of single consonants and triple consonants were constructed for use in the recognition threshold, forward masking by noise (peripheral) and backward masking by pattern (central) tasks. A set of 20 practice stimuli, consisting of 10 single consonants and 10 triple consonants, was also constructed. Single consonants were randomly selected under the condition that the same consonant did not appear on two consecutive trials. Triple consonants, which contained three unique letters, were matched for associative value $(38 \%)$, and were randomly selected from the list contained in Witmer. ${ }^{20}$

Target stimuli that contained a single consonant subtended a visual angle of 0.39 degrees vertically, 0.28 to 0.49 degrees horizontally, and had a stroke width of 0.08 degrees. Target stimuli that contained a triple consonant subtended a visual angle of 0.39 degrees vertically, $1 \cdot 13$ to 1.34 degrees horizontally, and had a stroke width of 0.08 degrees. The visual noise and pattern masks subtended a visual angle of 3.36 degrees vertically and $5 \cdot 11$ degrees horizontally.

Design

After the practice trials (10 single consonants, 10 triple consonants) were presented, each subject completed the three tachistoscopic tasks (recognition thresholds; monoptic, forward masking by noise; dichoptic, backward masking by pattern). The single target condition of each experimental task was presented before the triple target condition. The order in which the three experimental tasks were completed was varied across subjects, with a latin square design to control for fatigue and practice effects.

With the exception of a single patient with CHI (CHI02), subjects completed the three experimental tasks during a single test session. Patient CHI02 required two sessions due to fatigue. The experimental procedures required between 45 minutes and three hours to complete, because rest breaks were allowed between test conditions as needed.

\section{Administration procedures}

Subjects were seated in front of the tachistoscope and instructed to look at the central fixation point while the test procedures were explained. Before presenting each test stimulus the examiner said "ready?". When the subject said "yes" the examiner depressed a lever that initiated the trial. Figure 1 shows the sequence of events that occurred during each experimental task. After each trial, subjects were asked to report which letter (single target condition) or letters (triple consonant condition) were presented. When subjects were unsure, they were asked to guess. A card displaying the consonants was posted next to the tachistoscope to facilitate a recognition response when subjects did not spontaneously report the target.

\section{Presentation of practice trials}

The 10 single consonant practice trials were presented first. Two trials were presented at each of the following target durations ( $\mathrm{ms}$ ) in descending order: $160,80,40,20,10$. The triple consonant practice trials were then presented in the same manner. Under both conditions (single, triple), when a subject was unable to identify both stimuli at a specific target duration, the target duration was not decreased further on the remaining trials.

Presentation of experimental tasks:

\section{psychophysical technique}

A critical target duration (CTD) was obtained for each subject for each of the six experimental conditions (recognition threshold, single and triple consonants; forward masking, single and triple consonants; backward masking, single and triple consonants). These values were determined by an adaptive method. Target durations were initially set at $100 \mathrm{~ms}$ and decreased after a subject correctly identified a stimulus, or increased after a subject

Eye

Sequence

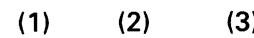

(4)

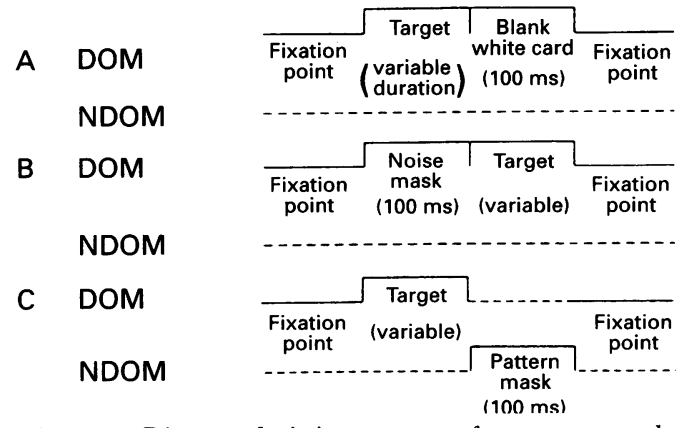

Figure 1 Diagram depicting sequence of events presented to dominant (DOM) and non-dominant (NDOM) eyes during experimental tasks: (A) recognition threshold, (B) forward masking by noise, (C) backward masking by pattern. The sequence of events for the 20 practice trials was identical to the recognition threshold task. $\left(--_{-}\right)=$Dark field. 
Figure 2 Example of psychophysical technique used to calculate critical target durations (CTDs) for each experimental condition. The numbers in parentheses indicate direction reversals. The target durations (TDs) corresponding to the 4th, 5 th, 6th and 7 th reversal are shown in upper right quadrant.

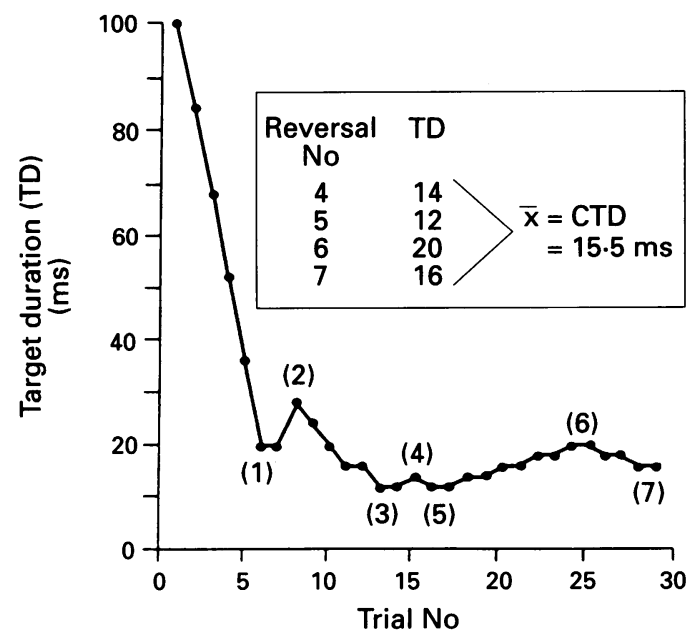

incorrectly identified two consecutive stimuli at the same target duration. Target durations were changed in $16 \mathrm{~ms}$ increments until the first direction reversal (for example, going from increasing to decreasing the target duration). The target duration was then changed in $8 \mathrm{~ms}$ increments until the second direction reversal followed by $4 \mathrm{~ms}$ increments until the third direction reversal. After the third direction reversal, the target duration was always changed in $2 \mathrm{~ms}$ increments. The procedure was discontinued after seven direction reversals. The CTD was then calculated by taking the arithmetical mean of the target durations employed on the trials which preceded the fourth, fifth, sixth, and seventh direction reversals (see example in fig 2). The target set size effect (CTD triple-CTD single) for each experimental task was also calculated to provide a measure of additional time required for the subjects to process the more complex stimuli.

\section{Results}

EXPERIMENTAL MEASURES

The data of the patients with $\mathrm{CHI}$ and controls were analysed by comparing their CTDs and target set size effects under each experimental condition. It was necessary to employ non-parametric statistics to analyse the data because of pronounced variability in the CTDs of the patients with $\mathrm{CHI}$ relative to controls (see fig 3 ).

Firstly, between group differences in the CTDs obtained under the single and triple target conditions and the target set size effect were tested for each experimental task by a series of Mann-Whitney $U$ tests. Wilcoxon signed ranked tests were then employed to assess within group differences in the CTDs obtained by subjects under single $v$ triple conditions of each task, and to compare the target set size effect across tasks.

BETWEEN GROUP COMPARISONS

Table 4 gives between group differences in the CTDs obtained under each experimental condition. The CHI group had longer CTDs than their matched controls under all conditions except the single letter condition of the backward masking by pattern task. Table 4 also shows that patients with $\mathrm{CHI}$ exhibited a greater target set size effect than their matched controls on each experimental visual processing task.

\section{WITHIN GROUP ANALYSES}

Both groups obtained significantly longer CTDs on the three tasks when the target was three consonants $v$ a single letter (table 5). The patients with $\mathrm{CHI}$ also exhibited a
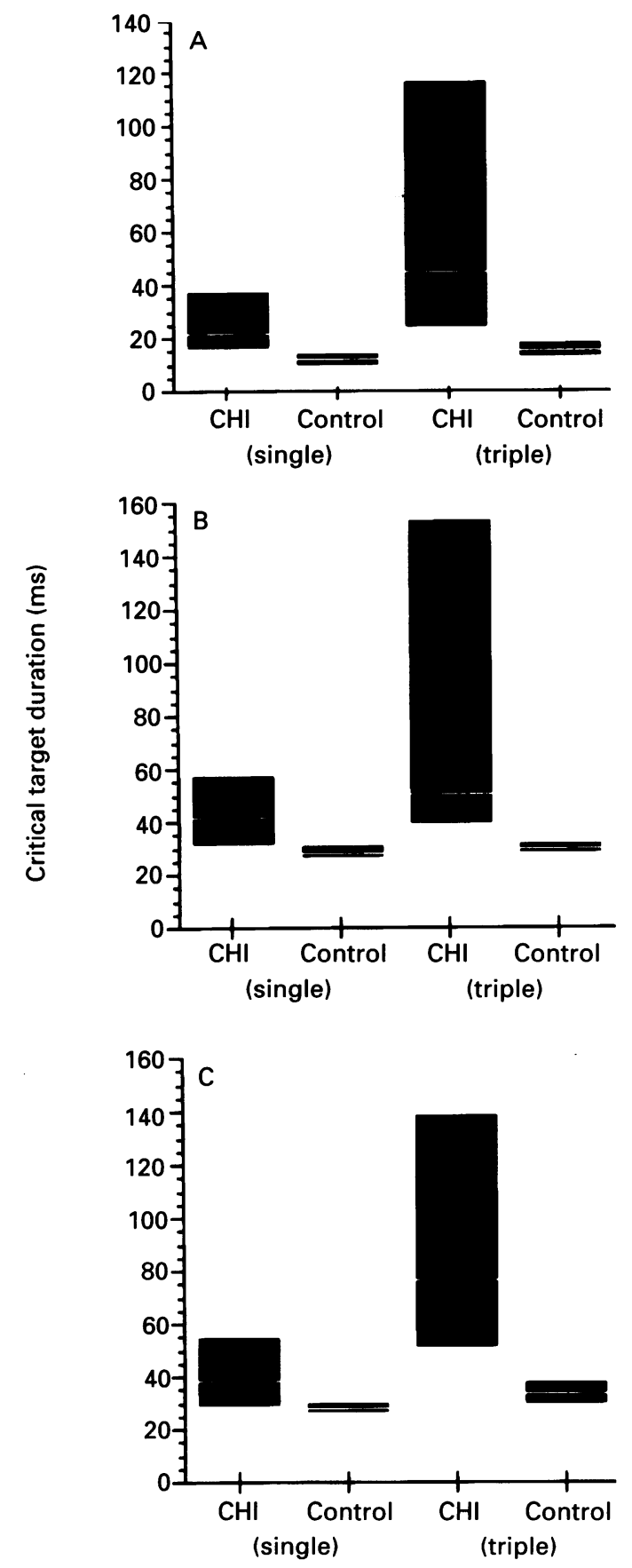

Figure 3 Boxplot of critical target durations (CTDs) obtained by subjects in each group on experimental tasks when single letters and triple consonants were used as targets: $(A)$ recognition threshold, $(B)$ forward masking by noise, (C) backward masking by pattern. The white lines indicate the median CTDs obtained and the bottom and top of the boxes indicate the 25th and 75th percentiles, respectively. 
Table 4 Between group comparisons on recognition threshold, monoptic forward masking by noise and dichoptic backward masking by pattern tasks

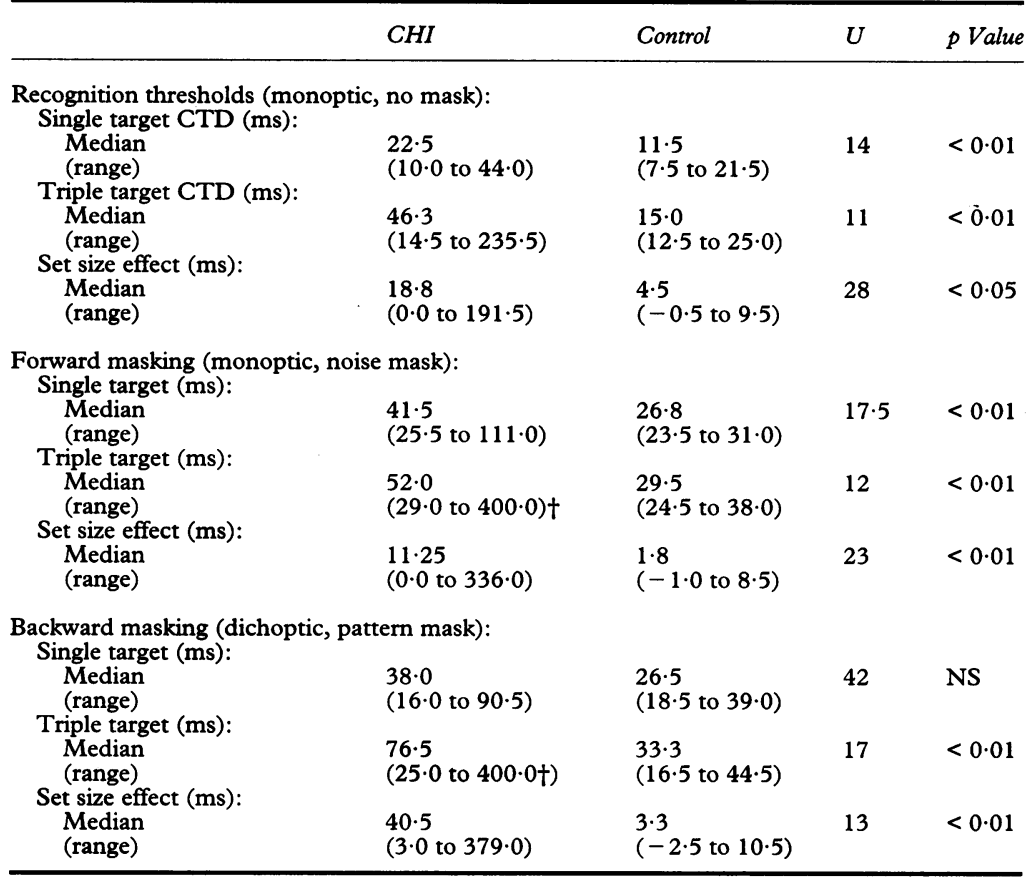

Mann-Whitney $U$ tests on CDTs, were obtained under single and triple conditions and on set size effect (CTD triple-CTD single).

†Testing discontinued at $400 \mathrm{~ms}$.
CHI obtained under the single letter target condition on the recognition threshold $(\rho=-0.650, \mathrm{p}<0.05)$ and forward masking tasks $(\rho=-0.643, \mathrm{p}<0.05)$. This relation between Glasgow coma scale score and CTD was not found on these tasks under the triple target condition. A similar but non-significant relation was found between Glasgow coma scale score and CTD for single targets on the backward masking task $(\rho=-0.556, p<$ $0 \cdot 10$ ). Injury to test interval (years since injury) was not significantly related to the CTDs obtained under any of the experimental conditions.

\section{Discussion}

On each experimental task, chronic survivors of severe $\mathrm{CHI}$ required longer exposure durations than their matched controls to identify visual targets presented tachistoscopically. The finding of increased threshold durations for recognition of single and triple letters (no mask condition) after $\mathrm{CHI}$ is consistent with previous tachistoscopic studies, ${ }^{56}$ which documented slowing or degradation of visual information processing in patients with $\mathrm{CHI}$. Also, our findings on both the monoptic, forward masking by visual noise and the dichoptic, backward masking by pattern tasks demonstrate that the sequelae of severe $\mathrm{CHI}$ include a disruption in perceptual processing within both peripheral and central visual pathways. ${ }^{14}$

A consistent relation was also found masking compared with the forward masking task $(W=3, p<0.01)$. By contrast, the set size effect obtained in control subjects did not significantly differ across the forward and backward masking tasks.

SPEARMAN RANK ORDERED CORRELATIONS A series of Spearman rank ordered correlations was also calculated to determine whether the CTDs obtained on each experimental condition were related to demographic variables or to injury characteristics. Age and education were not significantly related to the CTDs obtained by controls or patients with CHI on any of the experimental tasks. Severity of impaired consciousness, as reflected by Glasgow coma scale score, was related to the CTDs that the patients with

Table 5 Within subject effects of set size on recognition threshold, forward masking, and backward masking tasks: Wilcoxon signed ranked tests*

\begin{tabular}{lccc}
\hline & $\begin{array}{l}\text { Setsize† } \\
\text { Median (range) }\end{array}$ & $W$ & $p$ Value \\
\hline $\begin{array}{l}\text { Recognition threshold: } \\
\text { CHI }\end{array}$ & $18.8(0$ to 191.5$)$ & 0 & $<0.01$ \\
$\begin{array}{l}\text { Control } \\
\text { Forward masking: }\end{array}$ & $4.5(-0.5$ to 9.5$)$ & 1 & $<0.01$ \\
$\quad$ & & \\
CHI & $11.3(0$ to 336.0$)$ & 0 & $<0.01$ \\
Control & $1.8(-1.0$ to 8.5$)$ & 6 & $<0.01$ \\
Backward masking: & & & \\
$\quad$ CHI & $40.5(3.0$ to 379.0$)$ & 0 & $<0.01$ \\
Control & $3.3(-2.5$ to 10.5$)$ & 10 & $<0.05$ \\
\hline
\end{tabular}

‡Tests performed on single and triple CTDs.

tSet size $=($ CTD triple-CTD single $)$; results of within group, paired comparisons of the target set size effect (CTD triple-CTD single). between the time required to process a visual target and the amount of information contained in the target. Subjects in both groups identified single letter targets more quickly than triple consonants on the recognition threshold and on both forward and backward masking tasks. This effect of target set size indicates that as the complexity of visual input increases, more processing time is required to form a visual percept, even for normal controls. Presumably, complex visual tasks require a longer perception time than less complex visual tasks because the processing of figural aspects of visual input occurs at a relatively slow rate. ${ }^{21}$ Our findings also indicate that survivors of severe $\mathrm{CHI}$ consistently require more additional processing time than uninjured controls as the amount of information in target stimuli increases. Furthermore, by contrast with the relatively constant amount of additional time required by control subjects to process three targets ( $v$ single letters) across the three experimental tasks, the increment of time required by patients with $\mathrm{CHI}$ to process triple consonants varied with the visual task. The amount of additional time needed for patients with $\mathrm{CHI}$ to process more complex stimuli was significantly greater on the dichoptic, backward masking task than on the monoptic, forward masking task. This finding supports our earlier interpretation of performance on the forward visual masking task as reflecting the integrity of early sensory processing (which is presumably relatively unaffected by the complexity of the stimuli) and performance on the backward visual 
masking task as reflecting the integrity of higher order visual perception. We also interpret this finding to suggest that both preiconic and posticonic visual information processing stages are adversely affected by severe head trauma.

Impaired performance on the monoptic, forward masking task after severe CHI indicates that preiconic processing of visual stimuli is disrupted, and that this disruption occurs at or before the cortical site of binocular summation. In other words, severe CHI may cause slowed transmission of information from the retina to the cortex, or a reduction in the rate that essential features of the stimuli are extracted from input to the striate cortex and integrated into a composite representation (icon). Results on the dichoptic, backward masking task indicate that $\mathrm{CHI}$ also disrupts processing within central visual pathways. Central visual pathways are involved in both preiconic and posticonic processing. ${ }^{15}$ The fact that patients with $\mathrm{CHI}$ are particularly impaired on this task when the target stimuli are three consonants compared with single letters, however, suggests that the disruption occurs at posticonic information processing stages. Preiconic processing involves the initial registration of sensory information, and if only preiconic central processes were disrupted, identification of single letters and triple consonants would presumably be more equally impaired. Disruption, or slowing, of "read out" of information from iconic to posticonic store requires attention, ${ }^{15}$ and with more difficult or complex tasks (triple consonants $v$ single letters), more masking effects would be expected. Given the complexity of higher order visual perception and pattern

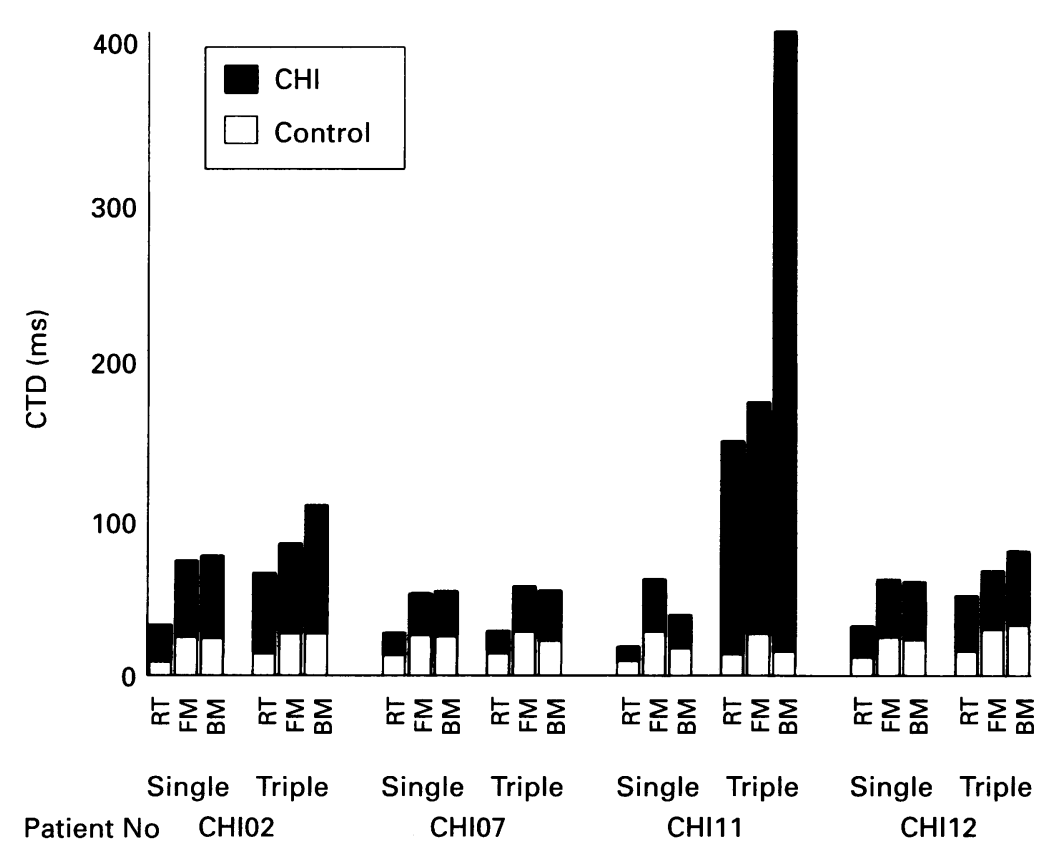

Figure 4 Histograms depicting critical threshold durations (CTDs) obtained by patients with CHI under the recognition threshold (RT), forward masking (FM), and backward masking (BM) conditions. Table 2 gives additional information about the patients. recognition, ${ }^{22}$ however, it seems that poor performance on the backward masking task after severe $\mathrm{CHI}$ could also potentially be caused by disruption of a number of other processes (for example, difficulty with the analysis and categorisation of information in iconic store). Short term memory impairments could also potentially contribute to poor performance by $\mathrm{CHI}$ subjects on the triple consonant condition of the backward masking task, by causing subjects to forget the second, or third letters, or both while reporting the first letter(s). In any case, further experiments are necessary to differentiate the contributions of peripheral $v$ central visual processes to the observed deficits of patients with $\mathrm{CHI}$ under the recognition threshold, forward masking, and backward masking conditions.

Control subjects showed relatively little variability in the durations of exposure required to identify visual stimuli under each test condition. This relative constancy of processing time in the controls indicates that the neural systems that subserve basic visual perception are relatively "hardwired". By contrast, performance on the visual processing tasks was highly variable in survivors of severe $\mathrm{CHI}$ (see fig. 4), and the degree of variability in the exposure durations needed by severely injured subjects to identify visual stimuli increased greatly with the amount of information to be processed. Given the heterogeneity after $\mathrm{CHI}$ in regard to the extent of diffuse axonal injury and type and location of focal lesions, ${ }^{23}$ the injured subjects' variability in performance on the experimental tasks is not surprising. Inspection of the data, however, did not reveal an obvious relation between impairments on the three tasks and CT findings or the presence of residual motor, speech and language, or visual impairment.

Our results indicate that time since injury is not related to the degree of impairment of visual processing after severe CHI. The patients with CHI in this study, however, had been injured at least one year before testing. In the light of Reusch's earlier finding that impairments in visual processing are most prominent during the acute stage of recovery after head trauma, it is possible that inclusion of patients studied earlier after injury might increase the correlation between performance on the tasks and injury to test interval. Severity of injury, which was characterised by a comatose state in all cases, seems to be inconsistently related to performance on the experimental tasks. Correlations between initial Glasgow coma scale score and the performance of patients with $\mathrm{CHI}$ on the single target condition of the recognition threshold (no mask) and forward masking tasks were significant, and the relation between Glasgow coma scale score and performance on the single target condition of the backward masking task approached significance. Initial Glasgow coma scale scores were not, however, significantly correlated with the CTDs obtained under the triple target conditions. The reason for this dissociation is not entirely clear, but we postulate that the extent of diffuse injury, 
reflected by GCS scores, influences the integrity of basic visual perceptual abilities, whereas the presence of focal lesions in brain areas associated with attention, memory, or higher order visual processing exerts an additional disrupting effect on visual perception, which becomes more evident as visual processing demands are increased.

This research was supported by grant NS-21889 and aided by grant in aid of research, Sigma Xi, The Scientific Research
Society. We are also indebted to Drs H J Hannay, J F Koetting, and $M$ Naus for their input and support while this study was being conducted and to Angela Thompson for word processing.

1 Van Zomeren AH, Deelman BG. Long-term recovery of visual reaction time after closed head injury. $\mathcal{F}$ Neurol Neurosurg Psychiatry 1978;41:452-7.

2 Stock LC, Gaillard AWK. Task and driving performance of patients with a severe concussion of the brain. 7 Clin Exp Neuropsychol 1986;8:421-36.

3 Levin HS, High WM, Goldstein FC, Williams DH. Sustained attention and information processing speed in chronic survivors of severe closed head injury. Scand $\mathcal{F}$ Rehab Med Suppl 1988;17:33-40.

Rehab Med Suppl 1988;17:33-40.
4 Van Zomeren AH, Brouwer WH, Deelman BG. Attentional deficits: The riddle of selectivity, speed, and Attentional deficits: The riddle of selectivity, speed, and alertness. In: Brooks N, ed. Closed head

5 Ruesch J. Dark adaptation, negative after images, tachistoscopic examinations and reaction time in head injuries. $\Im$ Neurosurg 1944;1:243-51.

6 Hannay HJ, Levin HS, Kay M. Tachistoscopic visual perception after closed head injury. $\mathcal{f}$ Clin Neuropsychol 1982;2:117-29.

7 Kahneman D. Methods, findings and theory in studies of visual masking. Psychol Bull 1968;70:404-25.

8 Breitmeyer BG. Visual masking: An integrative approach. New York: Oxford University Press, 1984.
9 Walsh DA. Age differences in central perceptual processing: A dichoptic backward masking investigation. f Gerontol 1976;31:178-85.

10 Walsh DA, Till RE, Williams MV. Age differences in peripheral perceptual processing: A monoptic backward masking investigation. $\mathcal{F}$ Exp Psychol Hum Percept Perform 1978;4:232-43.

11 Dilollo V, Arnett JL, Kruk RV. Age-related changes in rate of visual information processing. 7 Exp Psychol Hum Percept Perform 1982;8:225-37.

12 Dilollo V, Hanson D, McIntyre JS. Initial stages of visual information processing in dyslexia. $\mathcal{F}$ Exp Psychol Hum Percept Perform 1983;9:923-35.

13 Coyne AC, Liss L, Geckler C. The relationship between cognitive status and visual information processing. cognitive status and visual

14 Turvey MT. On peripheral and central processes in vision: Inferences from an information processing analysis of Inferences from an information processing analysis of
masking with patterned stimuli. Psychol Rev 1973;80: masking.

15 Michaels CF, Turvey MT. Central sources of visual masking: Indexing structures supporting seeing at a single, brief glance. Psychol Res 1979;41:1-61.

16 Teasdale G, Jennett B. Assessment of coma and impaired consciousness: A practical scale. Lancet 1974; ii:81-4

17 Harrington DO. The visual fields: a textbook and atlas of clinical perimetry. St Louis: Mosby, 1976.

18 Wechsler D. WAIS-R manual. New York: Psychological Corporation, 1981.

19 Reitan RM, Wolfson D. The Halstead-Reitan neuropsychological test battery: theory and interpretation. Tucson: Neuropsychology Press, 1985.

20 Witmer LR The association value of three-place consonant syllables. F Genet Psychol 1935;47:337-59.

21 Breitmeyer BG, Ganz L. Implications of sustained and transient channels for theories of visual pattern masking, saccadic suppression, and information processing. Psychol Rev 1976;83:1-36.

22 Klatzky RL. Human memory, 2nd ed. New York: Freeman, 1980

23 Adams JH, Graham DI, Gennarelli TA. Contemporary neuropathological considerations regarding brain damage in head injury. In: Becker DP, Povlishock JT, eds. Central nervous system trauma status report. Bethesda: National Institute of Neurologic Disorder and Stroke, 1985. 